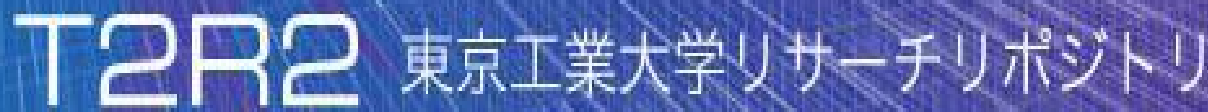

\section{Tokyo Tech Research Repository}

\section{論文 /著書情報 \\ Article /Book Information}

\begin{tabular}{|c|c|}
\hline Title & $\begin{array}{l}\text { Stimulated Emission from Spherical Particles -Thermal stability of } \\
\text { PTES-derived hybrid materials- }\end{array}$ \\
\hline Authors & Tetsuji Yano, Takahiro Kitajima, Akinori Araya, Shuichi SHIBATA \\
\hline & \\
\hline Citation(English) & SPIE, Sol-Gel O ptics VI, Vol. 4804, No. , pp. 60-68 \\
\hline & \\
\hline 発行日 /Pub. date & 2002 \\
\hline DOI & http://dx.doi.org $/ 10.1117 / 12.453887$ \\
\hline & \\
\hline 権利情報 /Copyright & $\begin{array}{l}\text { 本著作物の著作権はSociety of Photo-O ptical Instrumentation } \\
\text { Engineersに帰属します。 } \\
\text { Copyright } 2002 \text { Society of Photo-O ptical Instrumentation Engineers. } \\
\text { One print or electronic copy may be made for personal use only. } \\
\text { Systematic reproduction and distribution, duplication of any material in } \\
\text { this paper for a fee or for commercial purposes, or modification of the } \\
\text { content of the paper are prohibited. }\end{array}$ \\
\hline
\end{tabular}




\title{
Stimulated emission from spherical particles - Thermal stability of PTES-derived hybrid materials -
}

\author{
T. Yano, T. Kitajima, A. Araya and S. Shibata \\ Dept. of Chemistry and Materials Science, Tokyo Institute of Technology, Tokyo, Japan
}

\begin{abstract}
The effects of heat treatment on the optical quality of organic-inorganic hybrid spherical particles were investigated. The spherical particles with a diameter of $6 \mu \mathrm{m}$ were prepared via sol-gel process from phenyl-tetraethylsilane(PTES) using the vibrating orifice technique, and they showed strong oscillation signals based on the spherical resonance mode with low power threshold of the incident $\mathrm{CW}-\mathrm{Ar}^{+}$laser. Against the heat treatment on the slide glass plate, there were some particles which remained their spherical shape after $400^{\circ} \mathrm{C}$ heating depending on the condition of sol preparation. The survived particles were also found to have high photo-stability that they were not damaged from the laser irradiation of $514.5 \mathrm{~nm} \mathrm{Ar}^{+}$light with a power $>120 \mathrm{~mW} / \mathrm{particle}$, while as-prepared particles were bursted by the irradiation $<20 \mathrm{~mW} /$ particles. From the measurements of micro Raman scattering spectroscopy, optical and secondary electron microscope and thermal analysis, the thermal stability of hybrid materials was considered.
\end{abstract}

Keywords: spherical particle, optical cavity, organic-inorganic hybrid material, heat treatment

\section{INTRODUCTION}

Optical micro-cavity using a spherical particle with a diameter of $10^{1-2} \mu \mathrm{m}$-size has been extensively focused in a recent few decades, because they are expected to be utilized as the micro-optics like a light source of multiwavelengths, stimulated Raman amplifier, ${ }^{1,2}$ probes for near-field scanning optical microscopy, ${ }^{3}$ components of photonic crystals ${ }^{4}$ and so on. High Q-factor of oscillator means to encapsulate the light inside with high efficiency and the spherical shape enables three-dimensional encapsulation by reflecting the light at the spherical interface. Therefore, these optical phenomena in spherical particles can be caused with low threshold of the incident light.

In 1984 , lasing from dye-dissolved ethanol droplets in $60 \mu \mathrm{m}$ diameter was reported, ${ }^{5}$ not for the practical use, however, which is the revival of the spherical lasers. After the report, lasing from various dye-doped spherical particles have been demonstrated by many authors. Most of the employed media for the microspheres were liquid droplet and/or plastic containing optical dopants like laser dyes. However, these materials are never stable under the irradiation of strong laser beam in practice. In order to attain highly stable materials, the introduction of the inorganic constituents is indispensable remaining organic factors, because the former brings the structural rigidity into the particle while the latter causes the easy preparation of dense spheres at low temperature and also induces the flexible control of optical properties like refractive index, optical active dopants, etc.

Our group has been investigated the preparation and properties of spherical particles of organic-inorganic hybrid materials using sol-gel process. ${ }^{6-8}$ Phenyl-tetraethoxy-silane(PTES) has been used as the starting material to prepare a sol. Using the vibrating orifice technique for dividing the sol into droplets with a certain constant volume, we have prepared the $\mu \mathrm{m}$-size dense hybrid spherical particles with a remarkably uniform diameter within $0.1 \mu \mathrm{m}$. By doping florescent materials like laser dyes, lasing phenomenon showing the typical spectra of the spherical oscillator could be observed. In another paper of this conference, we presented that high-encapsulating ability of spherical particles was tested to increase the photostability in laser action

Further author information: (Send correspondence to S.S)

S.S: E-mail: sshibata@ceram.titech.ac.jp, Telephone: +81 35734 2522, Address: Ookayama 2-12-1, Meguro-ku, Tokyo 152-8552 Japan 
of laser dyes. The suitable conditions for long lifetime were investigated and the result showed that the $50 \%$ intensity maintained after more than 100,000 pulses of second harmonics of Q-switched Nd:YAG laser (532 nm wavelength).

However, the photo-stability of PTES-hybrid matrix against the laser irradiation has to be improved to higher level, because as-prepared particles still contain several factors to change the optical quality for oscillation like residual solvents, unreacted silanol etc. In this paper, the thermal stability and the photo-stability of spherical particles of PTES-hybrid materials were investigated. By heat-treating PTES-hybrid particles, we noticed that certain portion of the particles maintained their shapes absolutely after heating at high temperature, $400^{\circ} \mathrm{C}$. We also examined the viscoelastic behavior under heating by using PTES-hybrid film, and considered about optical quality of the particles for cavity function.

\section{EXPERIMENTAL}

\subsection{Sample Preparation}

Non-doped spherical particles of organic-inorganic hybrid material were prepared from Phenyltriethoxysilane (PTES). PTES was hydrolyzed in aqueous $\mathrm{HCl}$ solution of $\mathrm{pH}=3$ at $30^{\circ} \mathrm{C}$, and stirred for $40 \mathrm{~h}$ to proceed the polymerization of hydrolyzed PTES. After stopping stirring, the solution was separated into two layers. The lower layer was centrifuged twice and the resulted upper layer was removed carefully at the respective procedure. The obtained solution was diluted by ethanol with a volume ratio PTES solution:ethanol=1:174, and stored for aging at $30^{\circ} \mathrm{C}$ for $10-20$ days.

Particle formation was carried out using a vibrating orifice technique. The details about this preparation technique has been described in Ref. ${ }^{8}$ The parameters of this preparation technique were settled so that the droplets of $334 \mu \mathrm{l}$ in volume were atomized continuously from the orifice with a diameter of $20 \mu \mathrm{m}$. The liquid droplets from the vibrating orifice were dried during flying through a pipe with carrier dry air, and trapped in concentrated ammonium water(13.4mol/l) containing a surfactant Sodium-dodecylbenzen-sulfonate(DBSS) with $1.6 ! 1_{1} 0^{-3} \mathrm{~mol} / \mathrm{l}$. In this solution, the trapped particles were subsequently solidified. Here, DBSS avoids coagulation of solidified particles. The obtained spherical particles were washed by pure water several times, and used for the following treatments.

\subsection{Thermal analysis}

A thermogravimetric and differential thermal analyzer (TG-DTA, Rigaku dennki Co, Model TG8120) was used to monitor the evolution temperature of organic groups in PTES spherical particles. TG-DTA measurements of PTES hybrid spherical particles were carried out in temperatures from $20^{\circ} \mathrm{C}$ to $1000^{\circ} \mathrm{C}$ in air at a heating rate of $5^{\circ} \mathrm{C} / \mathrm{min}$.

For estimating the viscous-flow temperature of PTES hybrid materials, a film was prepared on a slide glass plate by dipping method from PTES sol after hydrolysis and polymerization reactions, and dried at $60^{\circ} \mathrm{C}$ for 2 days. Penetrating distance of a Ni probe pin into a PTES hybrid film was measured by the thermal analyzer (Rigaku denki Co, Model $\mathrm{CN} 8091 \mathrm{C} 1$ ) in the temperature from $20^{\circ} \mathrm{C}$ to $200^{\circ} \mathrm{C}$ at a heating rate of $10^{\circ} \mathrm{C} / \mathrm{min}$.

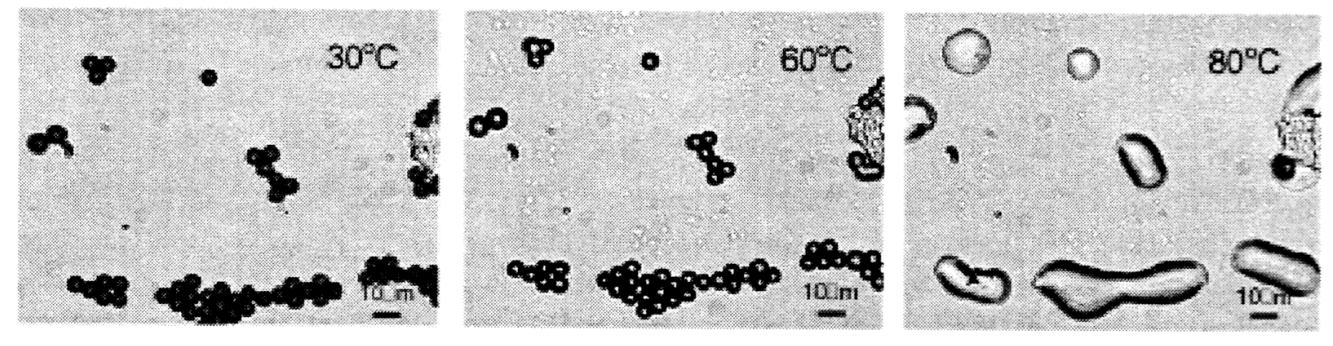

Figure 1. In-situ observation of spherical particles by an optical microscope. (White bar:10 $\mu \mathrm{m}$ ) 


\subsection{Heat treatment of spherical particles}

Spherical particles were placed on a slide glass plate and dried at $30^{\circ} \mathrm{C}$ for 1 day. They were heated with a heating rate of $30^{\circ} \mathrm{C} / \mathrm{h}$ up to a certain temperature and kept for $1 \mathrm{~h}$ in an electric resistance furnace under air. The heating temperatures were $100^{\circ} \mathrm{C}$ to $500^{\circ} \mathrm{C}$.

After heating, their shapes were checked by an optical microscope and by a secondary electron microscope (SEM). The change in their shapes was also observed in situ by an optical microscope with a heating stage from room temperature to $400^{\circ} \mathrm{C}$.

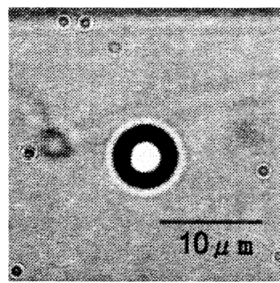

$30^{\circ} \mathrm{C}$

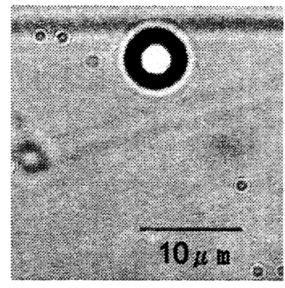

$200^{\circ} \mathrm{C}$

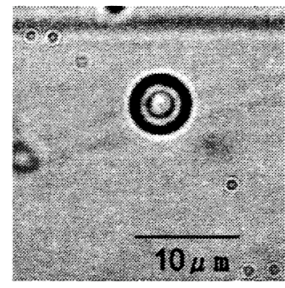

$300^{\circ} \mathrm{C}$

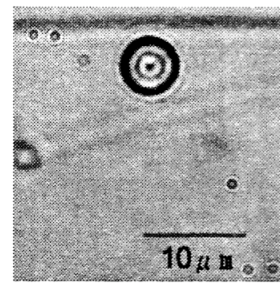

$400^{\circ} \mathrm{C}$

Figure 2. Photographs of spherical particles heat-treated at the respective temperature in air.

\subsection{Optical measurements}

The spherical particles heat-treated on a glass plate at various heating conditions were examined by using a microscopic Raman scattering spectroscopy(Jasco, Model NRS-2100). Excitation wavelengths were $488 \mathrm{~nm}$ and $514.5 \mathrm{~nm}$ of $\mathrm{CW}-\mathrm{Ar}^{+}$ion laser, and spectral resolution was $10 \mathrm{~cm}^{-1}$. When $514.5 \mathrm{~nm}$ excitation was used, the laser power was changed from $0.05 \mathrm{~mW}$ to $120 \mathrm{~mW}$. The incident laser beam was collimated to the size about $5 \mu \mathrm{m}$ in diameter.

\section{RESULTS}

Photographs of spherical particles taken in situ by an optical microscopy in heating from $30^{\circ} \mathrm{C}$ to $80^{\circ} \mathrm{C}$ are shown in Figs. 1. Major parts of spherical particles were melted down and lost their spherical shapes above $70^{\circ} \mathrm{C}$ heating. Small portion of spherical particles, however, maintained their shapes after heating at $100^{\circ} \mathrm{C} \sim 400^{\circ} \mathrm{C}$ as shown in Fig. 2. When the sol diluted by ethanol was aged for longer period of time, the portion of the survived particles remarkably increased. More than about $90 \%$ particles were found to maintain their spherical shapes absolutely, even when they were heated up to $300^{\circ} \mathrm{C}$.

Figure 3(a) shows a penetrating curve of a pin into a PTES hybrid film on glass plate in air. Above $80^{\circ} \mathrm{C}$, the penetration started and reached nearly $100 \%$ at $95^{\circ} \mathrm{C}$. Figure $3(\mathrm{~b})$ shows TG-DTA traces of non-doped PTES spherical particles in air. Weight loss about $5 \%$ started at about $100^{\circ} \mathrm{C}$ and completed below $400^{\circ} \mathrm{C}$. A large weight loss began above $400^{\circ} \mathrm{C}$. It reached to about $50 \%$ loss of the total weight at $600^{\circ}$, representing the oxidation and evolution of the organic groups (phenyl groups) from the particles. A DTA endothermic peak at about $550^{\circ} \mathrm{C}$ corresponds to the TG weight loss data.

In order to make clear the change in shapes of PTES spherical particles, secondary electron microscope(SEM) photographs were taken for the typical particles. Figures 4 and 5 show the appearance of the particles after heating. In the case that the portion of the survived particles was low (the aging time was short), they did not have only good spherical shapes but also smooth surfaces even when heated up to $400^{\circ} \mathrm{C}$ as shown in Fig. 4. On the other hand, the particles, most of which survived as a major part(the aging time was long), still have spherical shapes but contain inhomogeneous contrast of the brightness on the surface as in Fig. 5. This inhomogeneity was not observed on the surface of the as-prepared particles. Up to $500^{\circ} \mathrm{C}$, the surface roughness appeared clearly in the particles, which is not shown here. 

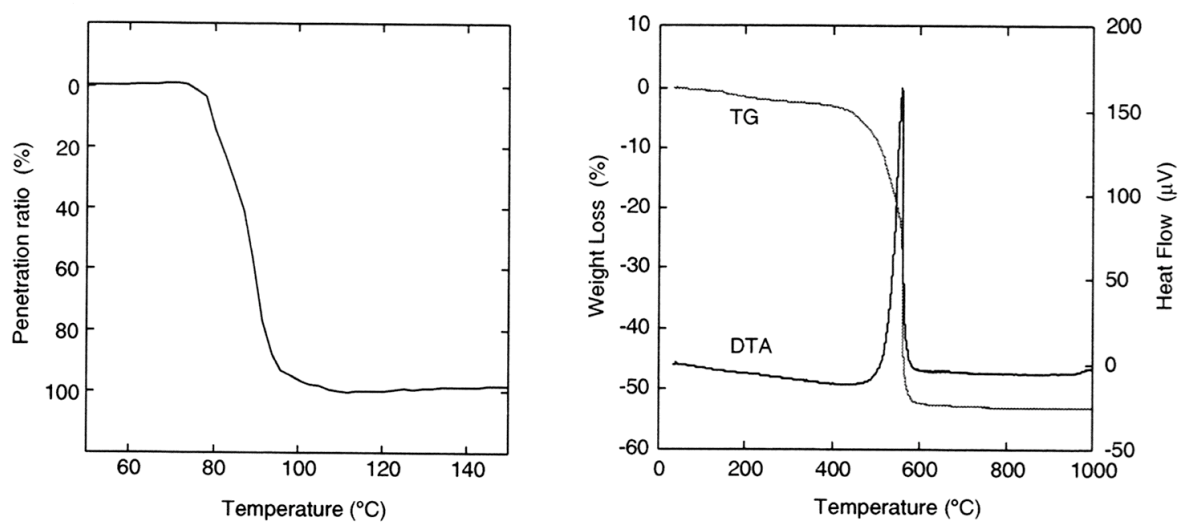

Figure 3. (a)Left: penetration ratio to a PTES-hybrid film. Heating rate $=10 \mathrm{~K} / \mathrm{min}$. (b)Right: TG and DTA traces of PTES-hybrid particles. Heating rate $=5 \mathrm{~K} / \mathrm{min}$.
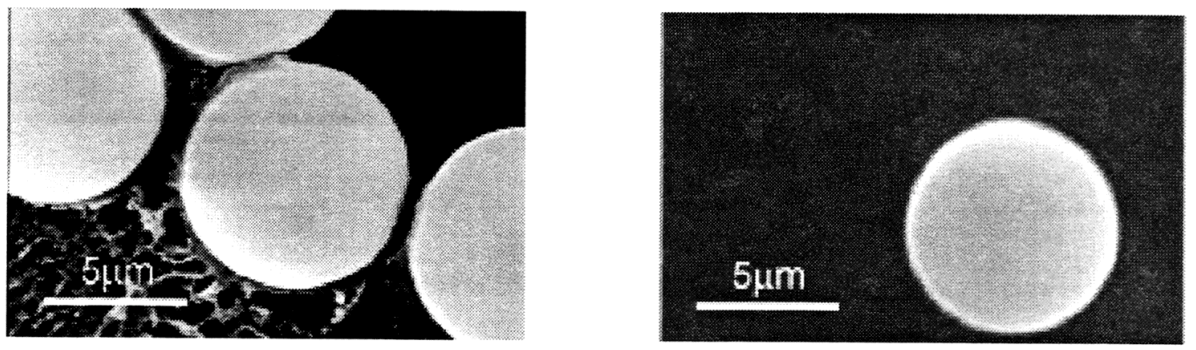

Figure 4. SEM photographs of spherical particles after heating at $200^{\circ} \mathrm{C}$ (left) and $400^{\circ} \mathrm{C}$ (right).

Typical spectrum excited by $\mathrm{CW}-\mathrm{Ar}^{+}$ion laser of $514.5 \mathrm{~nm}$ wavelength for the spherical particle dried at $30^{\circ} \mathrm{C}$ is shown in Fig. 6(a). Arrows showed the Raman scattering peaks due to phenyl groups in spherical particles. A pair of peaks can be attributed to the optical resonance in microsphere (whispering gallery modes, WGM). These oscillation modes could be clearly observed using the lowest power excitation about $50 \mu \mathrm{W} /$ particle. Under such low power excitations, Raman signals of phenyl group were quite low comparing with resonance signals, and oscillation modes could be observed over $5000 \mathrm{~cm}^{-1}$ in Raman shift(520-690 $\mathrm{nm}$ in wavelength).
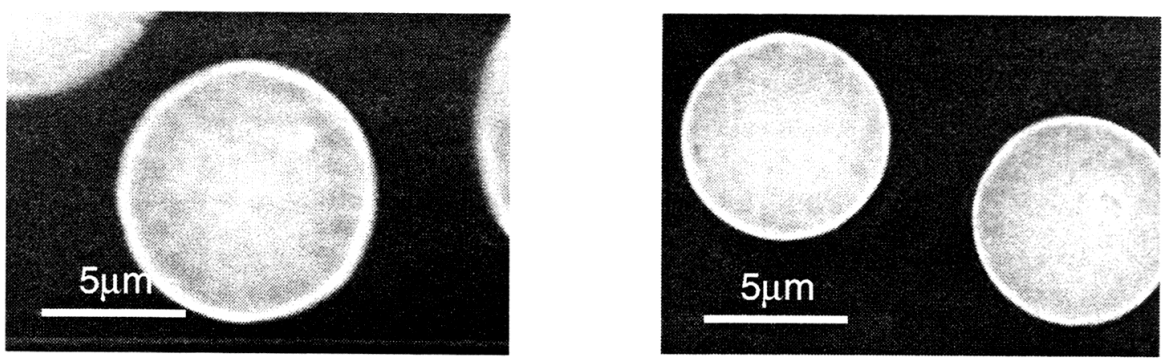

Figure 5. SEM photographs of spherical particles after heating at $200^{\circ} \mathrm{C}($ left $)$ and $300^{\circ} \mathrm{C}$ (right).

Mode spacing shown in Fig. 6(a) is known to have a correlation with the diameter of spherical particles. Figure 6(b) shows the relation between the particle diameter $a$ and the mode-spacing $\Delta \lambda$. The straight line is a theoretical linear line for this relation as a function of wavelength $\lambda$ and the relative refractive index $m$ between 
the particle and the surrounding subject(in this case, air);

$$
\Delta \lambda=\frac{\lambda^{2}}{2 \pi m a} \frac{\tan ^{-1}\left(m^{2}-1\right)^{1 / 2}}{\left(m^{2}-1\right)^{1 / 2}} .
$$

The data for the non-doped spherical particles were also plotted on the line and they were confirmed by the agreement of diameter by optical microscope photograph and that estimated by the relation.
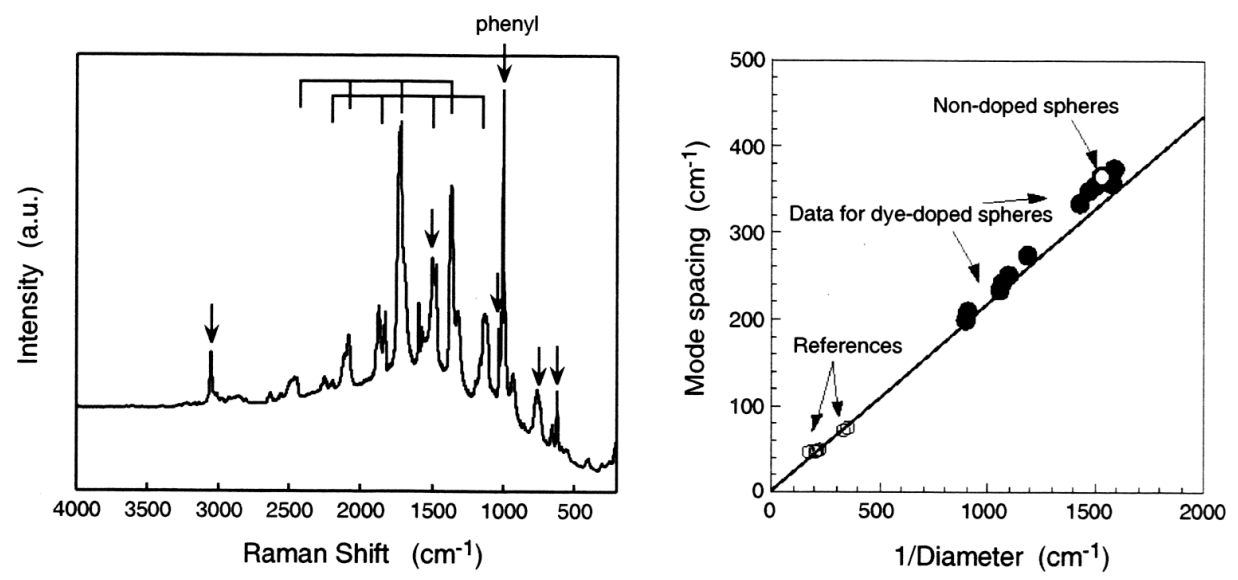

Figure 6. Left: Typical spectrum of non-dope spherical particle dried at $30^{\circ} \mathrm{C}$. Right: Relation between particle diameter and mode-spacing of various spherical particles.

Figure 7 shows Raman scattering spectra of the non-doped spherical particles after heating at different temperatures. A $10 \mathrm{~mW}-514.5 \mathrm{~nm}$ excitation was used. These were recorded for the survived particles in a series of the samples shown in Figs. 2 and 4. The individual optical images of the excited particles (in situ observation in the microscopic Raman measurements) are also shown at the right hand side of the figures. The samples from $30^{\circ} \mathrm{C}$ to $200^{\circ} \mathrm{C}$ showed both of the resonance peak due to WGM modes and the Raman scattering due to phenyl groups. In the $300^{\circ} \mathrm{C}$ and the $400^{\circ} \mathrm{C}$ samples, just the Raman scattering bands assigned as phenyl groups were remained. In $500^{\circ} \mathrm{C}$ sample, peak was not observed at all. From the optical images, light rings near the surface of spherical particles were observed in $30^{\circ} \mathrm{C} \sim 300^{\circ} \mathrm{C}$ samples, while above $400^{\circ} \mathrm{C}$ the ring did not appear. In the case of the particles from the sol aged for long time, WGM oscillation modes was observed only from the particles heated at the temperature lower than $100^{\circ} \mathrm{C}$.

The power of the excitation laser source changed from $0.05 \mathrm{~mW}$ to $120 \mathrm{~mW}$. The heat-treatment improved the photo-stability of the particles remarkably. The particles heat-treated above $200^{\circ} \mathrm{C}$ were not affected even when a $120 \mathrm{~mW}$ laser irradiation was focused. The as-prepared particles, which were not subjected to the heat treatment, burst immediately under the irradiation with the laser power over $20 \mathrm{~mW}$.

Finally, the dependence of the excitation wavelength was shown in Figs. 8 and 9. The spherical particles heated at $200^{\circ} \mathrm{C}$ were irradiated by different wavelengths of the $\mathrm{Ar}^{+}$ion laser, $488 \mathrm{~nm}$ and $514.5 \mathrm{~nm}$ wavelength, and the emission spectra were measured. The spectra of Fig. 8 are plotted against Raman shift (wavenumber, $\left.\mathrm{cm}^{-1}\right)$. In Fig. 9, the same spectrum data were plotted against wavelength $(\mathrm{nm})$. Raman scattering peaks due to the phenyl groups were observed in the same wavenumber in Fig. 8 (indicated by arrows). Thus the spectra involved the Raman scatterings. On the other hand, as shown in Fig. 9, the resonance peaks excited by different wavelengths were located at the similar wavelengths. 


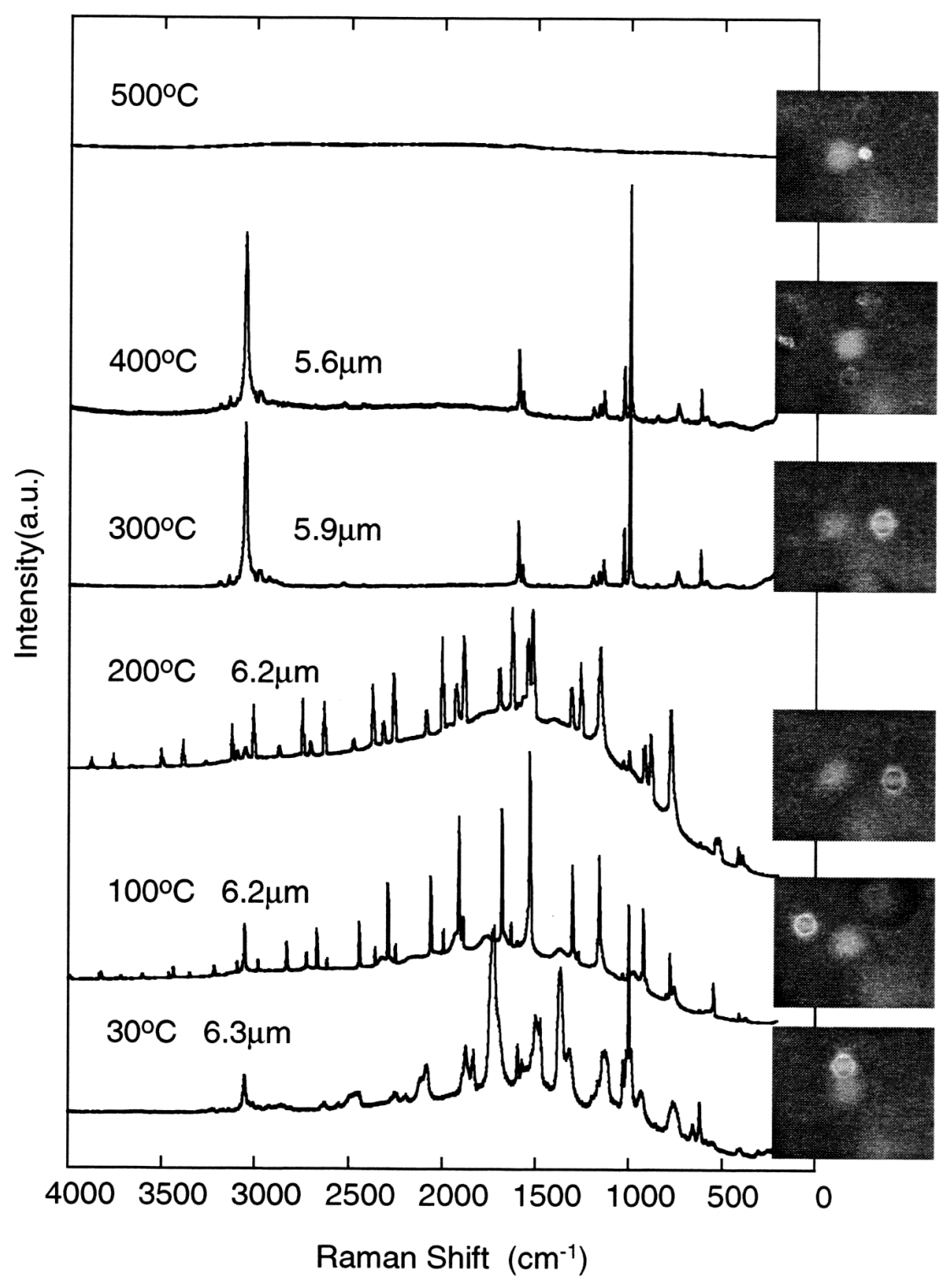

Figure 7. Raman scattering spectra of the spherical particles after heating at different temperatures. The values above the respective spectrum represent the diameters of the examined particles measured from the captured view by a CCD camera in Raman microscope. 


\section{DISCUSSION}

According to Ref., ${ }^{9,10}$ quality(Q)-factor of cavity oscillator is known to be governed by several factors expressed by the following equation.

$$
Q^{-1}=Q_{r a d}^{-1}+Q_{s . s .}^{-1}+Q_{m a t}^{-1}+Q_{c o n t}^{-1},
$$

where $Q_{\text {rad }}^{-1}, Q_{s . s .}^{-1}, Q_{m a t}^{-1}$ and $Q_{\text {cont }}^{-1}$ express the contribution by the intrinsic curvature loss, the surface scattering loss, the intrinsic material loss and the contamination loss on the surface, respectively.

The vibrating orifice technique for the fabrication of spherical particles has a great importance that the particles are solidified maintaining the free-surface without contact with other solid subject. As found in the oscillating signals due to WGM in the spectra(Fig. 6(a)), as-prepared particles are considered to have high Q-values.

In order to maintain high Q-factor of the PTES-hybrid spherical particles during heat-treatment, we have to pay much attentions to the first three factors in the above equation. The penetration trace of PTES-film reveals that PTES hybrid material becomes liquid state(melt) at the temperature at around $80^{\circ} \mathrm{C}$ during heating. Above such a temperature, a main force to maintain a spherical shape of the particles(droplet) is considered to be a surface tension between hybrid material and air and that between hybrid material and a slide glass substrate.

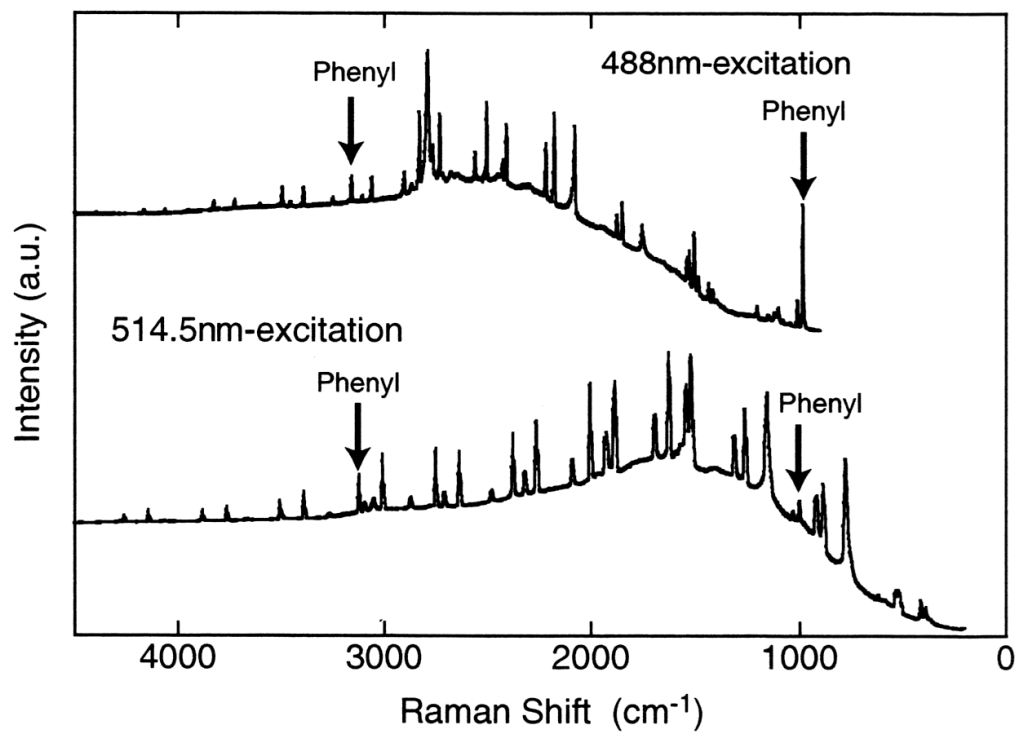

Figure 8. Raman scattering spectra of the particle heat-treated at $200^{\circ} \mathrm{C}$. The excitation wavelengths were $488 \mathrm{~nm}$ and $514.5 \mathrm{~nm}$. The arrows indicate Raman signals from phenyl groups.

Most of particles prepared from the sol after aging for a short time period could not maintain their spherical shape, and small portion could survive on the glass substrate. As found in in-situ observation(Fig. 1) and in SEM photographs(Fig. 4), the smooth surfaces of the samples show that surface tensions did actually work as one factor to maintain a spherical shape during heating. Fortunately, the particles heat-treated at $200^{\circ} \mathrm{C}$ could work as an optical cavity for WGM oscillation as shown in Fig. 7.

Further increase of temperature, on the other hand, would also proceed the heat-curing of hybrid materials, mainly due to the polymerization reactions between residual silanol groups in the particles. A slight weight loss about $5 \%$ below $400^{\circ} \mathrm{C}$ should be considered to be due to loss of the evolved water from the particles.

On the other hand, there were particles most of which survived to the heat-treatment even at $300^{\circ} \mathrm{C}$. The starting sol from which these particles were prepared had been aged for longer time period than the formers, and 


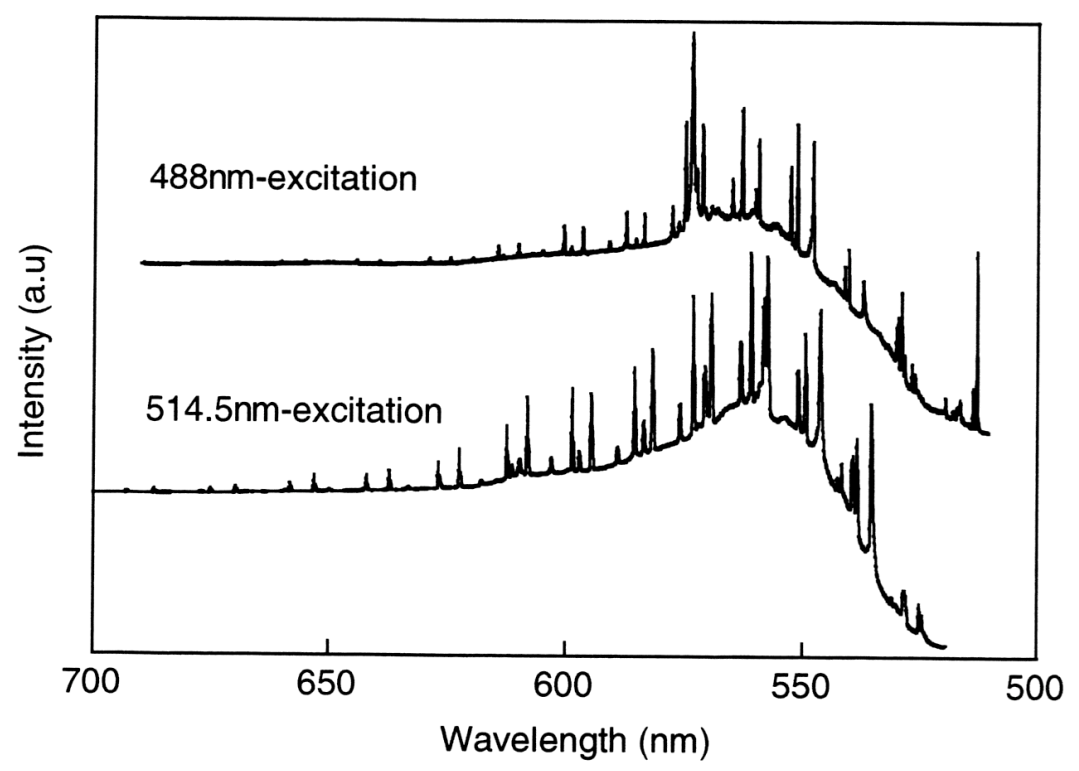

Figure 9. Emission spectra of the spherical particles excited by different wavelengths. These were calculated from the spectra in Fig. 8.

the degree of polymerization of oligomers in solution would have become large. In stead of this, the obtained particle surfaces have inhomogeneous appearance, and are considered to have high surface scattering loss, or high intrinsic material loss to reduce Q-factor of these particles. As a result, WGM oscillation could be observed only in the particles heated below $100^{\circ} \mathrm{C}$. Therefore, the oligomers in ethanol solution would be one of important factors to control thermal stability of hybrid spherical particles.

In our previous work, ${ }^{8}$ we have already reported that the aging time affected the surface irregulation even in the as-prepared PTES hybrid particles(the aging for more than 50days induced large irregulation of the particle surface). In this meaning, further optimization of the aging time would be required to control thermal stability of PTES hybrid materials. In order to answer to the question how these particles differ, structural informations of these materials are needed.

In addition to this, chemical interactions of a surfactant DBSS should be considered for the survival of the particles. DBSS was added to the ammonia water trap in order to avoid the coagulation the droplets(generated by the vibrating orifice technique) in solidification process. DBSS molecules cover PTES particles, and their dodecyl-chains separate the particle(droplet) from a glass substrate. Thus some of the particles were heated on the soft bed of DBSS molecules. Typical example can be seen in Fig, 4(the left side photograph). This protecting behavior of the particle surface might be another probable factor to decide the thermal stability of PTES hybrid particles.

Finally, the most extraordinary results were concentrated in Fig. 7, the spherical particles still showed the resonance peaks after $200^{\circ} \mathrm{C}$ heating. From the results of TG-DTA and Raman scattering, the organics(phenyl groups) were still involved in the particles after $400^{\circ} \mathrm{C}$ treatments. As described above, the shapes of spherical particles still remained at $400^{\circ} \mathrm{C}$. Thus, there is no doubt that the cavity function can be survived at $200^{\circ} \mathrm{C}$, but what is the origin of the resonance peaks? Two possibilities should be discussed for the origins: Raman gain of the phenyl-(O-Si-O $)_{n}$ - network structure, or photoluminescence caused by some structural defects. The results of Figs. 8 and 9 are helpful to consider the origin. If the origin is the photoluminescence, the shape of the emission spectra should not change even when the excitation wavelength is varied, such as $488 \mathrm{~nm}$ and $514.5 \mathrm{~nm}$ (see Fig. 9). At first, we are afraid of the contamination of dye from the equipment for particle preparation. The possibility of contamination seems to be small, because R6G dye cannot survive after $200^{\circ} \mathrm{C}$ heating. Consequently, although still origin is unclear, the PTES-derived spherical particles showed remarkable 
thermal stability, and maintained their shapes up to $400^{\circ} \mathrm{C}$ and the cavity function to $200^{\circ} \mathrm{C}$.

\section{ACKNOWLEDGMENTS}

The authors would like to thank Prof. M. Yamane for his guidance and helpful discussion.

\section{REFERENCES}

1. H. -B. Lin and A. J. Campillo, "cw Nonlinear optics in droplet microcavities displaying enhanced gain," Phys. Rev. Lett. 73, pp. 2440-2443, 1994.

2. S. M. Spillane, T. J. Kippenberg and K. J. Vahara, "Ultralow-threshold Raman laser using a spherical dielectric microcavity," Nature 415, pp. 621-623, 2002.

3. T. Kataoka, K. Endo, Y. Oshikane, H. Inoue, K. Inagaki, Y. Mori, H. An, O. Kobayakawa and A. Izumi, "Development of a scanning near-field optical microscope with a probe consisting of a small spherical protrusion," Ultramicroscopy 63, pp. 219-225, 1996.

4. J. D. Joannopoulos, R. D. Meade and J. N. Winn, Photonic Crystals, Princeton University Press, 1995.

5. H. M. Tzeng, K. F. Wall, M. B. Long and R. K. Chang, "Laser emission from individual droplets at wavelengths corresponding to morphology-dependent resonance," Opt. Lett. 9, pp. 499-501, 1984.

6. S. Shibata, M. Yamane, K. Kamada, K. Ohta, K. Sakai and H. Masuhara, "Laser emission from dye-doped organic-inorganic particles of microcavity structure," J. Sol-Gel Sci. Technol. 8, pp. 959-964, 1997.

7. S. Shibata, T. Yano and M. Yamane, "Dye-doped spherical particles of optical cavity structure," SPIE Sol-Gel Optics !\&3136, pp. 68-, 1997.

8. S. Shibata, A. Tomizawa, H. Yoshikawa, T. Yano and M. Yamane, "Preparation of spherical particles by vibrating orifice technique," SPIE Sol-Gel Optics V, 3943, pp.112-119, 2000.

9. M. L. Gorodetsky, A. A. Savchenkov and V. S. Ilchenko, "Untimate Q of optical microsphere resonators," Opt. Lett. 21, pp. 453-455, 1996.

10. D. W. Vernooy, V. S. Ilchenko, H. Mabuchi, E. W. Streed and H. J. Kimble, "High-Q measurements of fused-silica microspheres in the near infrared," Opt. Lett. 23, pp. 247-249, 1998. 